\title{
Learned Helplessness in Public Administration: The Case of San Diego City
}

\author{
Fatih Yüksel \\ Professor, Ondokuz Mayıs University, Economics and Administrative Sciences Faculty, \\ Public Administration Department, Samsun, Turkey, Email: fyuksel@omu.edu.tr \\ Yousef A. Ibrahim \\ Adjunct professor, Alliant International University, School of Management, San Diego, CA, USA, \\ Email:Smyyai@yahoo.com \\ Saba Senses Ozyurt \\ Assistant Professor, Alliant International University, School of Management, San Diego, CA, USA, \\ Email:sozyurt@alliant.edu
}

\section{Doi:10.5901/mjss.2015.v6n2p151}

\section{Abstract}

Learned helplessness is a psychological and cognitive process and state of mind when an individual remains unresponsive to new stimuli because of past experiences of (perceived) failure, which prevent subsequent learning. The state of learned helplessness could have an adverse effect on the employee productivity and could hinder adequately utilizing the human resources that are so critical to entities. It is shown that learned helplessness lies behind many problems such as unwillingness to work and perform operations or tasks as a matter of form; inability to engage in new and innovative thinking and practices; and incapability to go beyond routine works and operation. The objective of the present study is to identify factors that lead to learned helplessness among public sector employees. Specifically this article examines the relationship between the San Diego Municipal employees' seniority level, position and demographic characteristics and their levels of learned helplessness. The survey results indicate that learned helplessness is correlated with the position, seniority, education and age of public sector employees; however gender was not correlated with helplessness.

Keywords: Learned Helplessness, Public Administration, San Diego City

\section{Introduction}

Learned helplessness is when an individual remains unresponsive because past events and experiences prevent subsequent learning. This is a state that can occur in many environments including the work environment. The state of helplessness that has adverse influence on the employee productivity is a substantial problem preventing adequately utilizing the human resources that are critical to entities. Attitudes and behaviors of learned helplessness can be observed in the public sector. However, available literature does not address this issue with regard to public administration. It is shown that learned helplessness lies behind many problems such as unwillingness to work; unwillingness to work and perform operations or tasks as a matter of form; inability to engage in new and innovative thinking and practices; and incapability to go beyond routine works and operation. Existence of these symptoms may indicate learned helplessness in the public sector. As such, the objective of this study is to identify the relationship between San Diego Municipal employees' seniority level, position and demographic characteristics and learned helplessness. The paper will first address the concept, occurrence and development of learned helplessness. Then the findings of our research on San Diego Municipal employees will be presented.

\section{The Concept of Learned Helplessness ${ }^{1}$}

Learned helplessness is a process and state of mind in which previous experiences of percieved failure have a negative

1 This section has been taken from Fatih Yüksel and Ahmet Özkiraz (2012), "The main problem of Turkish public administration: Learned helplessness", African Journal of Business Management Vol. 6(4), pp. 1214-1221. 
effect on further learning, which makes an organism unresponsive to new but similar stimuli. If the organism believes that the outcome of a situation will be independent of its response, the organism will fail to respond in order to escape or avoid when it is faced with similiar problems due to learned helplessness. Similarly, when a person is faced with a situation to which he has previously been exposed to and was helpless to control the situation, this prior learned helplessness will interfere with the latter learning and performance.

Learned helplessness can also lead to a range of psychological disorders (Overmier, 2002:4). When an individual perceives that there exists no relation between his responses and the outcome (his control over the situation and the events), this perception will possibly affect his further responses (continuity of the uncontrollability). He will attribute the undesired outcome to internal, general and stable factors and this will lead to loss of self-confidence (Kümbül, 2006:62), and various sorts of psychological disorders -cognitive, motivational and emotional (Maier \& Seligman, 1976). A person who is frequently exposed to negative outcomes tends to lose his belief and confidence that he may control situations. As a result, the suceptibilty to to depression and other motivational, coginitve and emotional disorders is likely to increase (Günay \& Nursen, 2006:84).

There have been many studies published on this issue. Early studies were experiments with animals (Seligman \& Maier, 1967). Later, findings of these animal studies were experientially tested on humans (Hiroto, 1974). The findings showed that, even though less striking compared to those with animals, a learned helplessness response was easily induced in humans when they were placed in situations where they felt an inability to change or terminate an undesirable situation. Hiroto (1975) further tested the frequency of the helplessness caused by uncontrollable situations. The experiment was carried out in four different ways on university pupils: First, the unescapable and also the controllable tone were given subsequent to the shuttle-box escape/avoid test. The second was an anagram (rearranging the letters of words) test in which the subjects were asked to produce new words through the letters already blended. Afterwards, solvable and unsolvable discrimination problems were used. Third, the unescapable and controllable tone was given following an anagram-solving test. As for the fourth step, the unsolvable and solvable discrimination problems test was given following the shuttle-box escape/avoid test. With this four-step experiment, it was aimed to test learned helplessness in instrumental (to avoid the tone by an instrument) and cognitive (to produce meaningful words through blended letters) terms. The experiment had three main findings: First, the group that was exposed to the tone at an unavoidable level performed poorly in shuttle-box test whereas the group that had control over the tone performed well. This finding is in line with that of an experiment carried out on humans in 1974. Furthermore, the results of the learned helplessness experiments on humans share similarities with those on dogs, cats and rats. Second, it was detected that the group pretreated with four different insoluable problems performed poorly at anagram-solution compared to the control-group and avoidance-group. This finding shows that the cognitive tasks without any instrumental factor could lead to learned helplessness. Third, a certain relation between different sorts of helplessness was found. In other words, the performance of the group pretreated with unsolvable cognitive problems was debilitated at instrumental escape from the tone. Interestingly enough, this group became weakened to the same degree as the one pretreated with the instrumental avoidance test. Moreover, the group tested with the unavoidable tone performed as poorly as the subjects who were given four unsolvable discrimination problems at anagram-solution test. This experiment showed that the frequency of learned helplessness (i.e. reappearance of learned helplessness in various cases) may transform helplessness into a personality trait (Hiroto, 1975:311, 324-325). A helplessness experiment with an anagram test has been carried out in order to assess the situation of learned helplessness which follows helplessness with a short latency of 0-30 mins. and with a long latency of 2-6 hours. Consequently, all the subjects have been observed to be helpless. Subjects who were given the test following the short latency performed more poorly than those with the long tatency (Young \& Allin, 1992:135). This shows that there will be a remission in helplessness behaviours in the course of time following the event which led to helplessness (Yüksel, Özkiraz:1215).

Abramson and Seligman revised Hiroto's experiments becuase he did not make a distinction between personal helplesness and universal helplesness, and his experiments lacked a clear conclusion as to whether helplessness was general or specific, or, chronic or acute. Abramson and Seling's findings suggested that individuals attribute the existing situation to internal versus external factors. This attribution determines whether helplessness in the future will be chronic or acute, and if it will reduce self-esteem or not (Abramson \& Seligman, 1978:49). When a person compares himself to the other people, he will attribute the situation which he is in to internal factors if his tendency to be exposed to this situation is higher than those of the others, on the other hand, if the tendency is identical and/or similar among all the people, then the attribution should be external. For example, if a student is the only one to fail a course whereas the rest of the class have all passed, he will attribute the outcome to his intellectual deficiency, and therefore, he will become personally helpless. However, if the most of the students have failed, then the student will attribute this situation to the fact that the examinations have been hard and that the teachers have given low marks to all the students, which is an 
example to universal helplessness. Actually, in each situation, there comes the attitude that studying will have no effect on the outcome, and thus, no more effort will be made to change it (Abramson \& Seligman, 1978:52). Table 1 shows if a student attributes his low mark in Mathematics to his mental deficiency (internal, stable, personal) or if he attributes it to being tired (internal, instable, global) and to the fact that the exam has been unjust (external, instable, global), he will become unresponsive to his upcoming oral examination, thinking that the outcome will be completely independent of his response. However, so long as the student attributes the low mark to his lack of mathematical skills (internal, stable, personal) or to being fed up with Maths (internal, instable, personal) or to the injustice of the examination, he will never be helpless in his oral examination (Abramson \& Seligman, 1978:52, 57-58).

Table 1. Formal Properties of the Attribution Through An Example

\begin{tabular}{|l|l|l|l|l|}
\hline & \multicolumn{1}{|c|}{ Internal } & \multicolumn{1}{c|}{ Sxternal } \\
\hline \multicolumn{1}{|c|}{ Size } & \multicolumn{1}{|c|}{ Stable } & \multicolumn{1}{c|}{ Instable } & \multicolumn{1}{c|}{ Stable } & \multicolumn{1}{c|}{ Instable } \\
\hline $\begin{array}{l}\text { General } \\
\text { Unsuccessful } \\
\text { students }\end{array}$ & $\begin{array}{l}\text { Mental Deficiency } \\
\text { Laziness) }\end{array}$ & $\begin{array}{l}\text { Tiredness (What stupifies me is } \\
\text { common cold) }\end{array}$ & $\begin{array}{l}\text { Exam was not fair. (People } \\
\text { are usually unsuccessful at } \\
\text { these exams.) }\end{array}$ & $\begin{array}{l}\text { Today is Friday the 13th. } \\
\text { (Everbody has experimentally } \\
\text { been tested out. It was difficult for } \\
\text { anybody) }\end{array}$ \\
\hline $\begin{array}{l}\text { Specific } \\
\text { Unsuccessful } \\
\text { students }\end{array}$ & $\begin{array}{l}\text { Deficiency of } \\
\text { Mathematical } \\
\text { Skills } \\
\text { (Maths always } \\
\text { bores me) }\end{array}$ & $\begin{array}{l}\text { Getting fed up with } \\
\text { Mathematical problems } \\
\text { (Common cold rusts my } \\
\text { arithmetical knowledge) }\end{array}$ & $\begin{array}{l}\text { Maths exam was not fair. } \\
\text { (People are usually } \\
\text { unsuccessful at Maths } \\
\text { exams) }\end{array}$ & $\begin{array}{l}\text { Maths test was of the number 13. } \\
\text { (All the test orders were mixed) }\end{array}$ \\
\hline
\end{tabular}

Source: Abramson \& Seligman, 1978:57

\section{Learned Helplessness in Public Administration}

Learned helplessness in organizations and work environment can occur due to individual characteristics and/or the culture and management approach adopted by the organization. An employee who is apathetic towards his work has adverse influence on the environment, giving rise to organizational learned helplessness. Learned helplessness that emerges organizationally is regarded as a disease, and treatment of this disease becomes important in terms of success of the organization (Kümbül, 2006:183).

In public administration systems, many problems can occur regarding employee's attitudes and behaviors such as unwillingness to work and effectively perform tasks; inability to engage in new and innovative thinking and practices; incapability to go beyond routine work and operations; being attached to conventional (traditional) methods; merely carrying out the orders; exerting effort as needed and not going beyond that; reluctance to develop oneself; low motivation; making an effort that is far below knowledge, skills and abilities required by the job. Such low performance at the job partly stems from the belief that the existing public system would not change, and/or one's own power would not be adequate to change it. Human capital is a critical resource of public administration and learned helplessness hinders the effective use human resources the public sector. This impact of learned helplessness on public administration effectiveness has not been investigated and might have a particularly significant negative impact on the development of developing countries.

As a precursor of organizational change, organizational learning is a critical process that helps organizations adapt to environmental changes and demands through change in behavior and acquisition of new knowledge (Espejo et al 1996:90-91; David, 1993:78-91). Learned helplessness ultimately prevents organizational learning in public administration. According to this definitions, the relationship between the organizational learned helplessness and the organizational learning and change becomes more apparent. Organizational learned helplessness is more likely to exist in organizations with large number of employees experiencing personal learned helplessness, and inhibit organizational learning. Change, innovation, adapting to the environment, efficiency, productivity, and achieving mission become more difficult in organizations with poor organizational learning. Thus, both individual and organizational adverse consequences of learned helplessness begin to occur (Yüksel, 2012:1220).

\section{The Relationship between the Seniority, Position and Demographic Characteristics and the Helplessness}

Since the literature includes few studies on learned helplessness in the work place, there is no available knowledge 
whether helplessness is related to seniority, position and demographic characteristics. This study, for the first time, attempts to explore this relationship through survey data collected from the City of San Diego employees.

In view of the fact that learned helplessness is a state of mind in which an individual remains unresponsive to change situations and loses self-confidence because of previous failures which prevent subsequent learning, several predictions can be put forth on the expected relationship between the dependent and independent variables. First, seniority of the employee is expected to be positively correlated with learned helplessness in a work environment, as length of tenure in a job determines the number of opportunities for perceived failures and unresponsiveness, and increases the chances of experiencing/reinforcing learned helplessness. Thus, it is likely to observe differences in the level of learned helplessness based on the length of time an individual is employed in the public sector.

A similar prediction can be put forth about being in a management position. Those who are in a management position are expected to experience less learned helplessness than those who are not in a management position because they are more likely to control and change the existing conditions. Those who are not in a management position are expected to become more affected by unfavorable environmental conditions and to experience learned helplessness as they have less power to change the organization.

Finally it can be predicted that demographic factors including education, age and gender would impact learned helplessness. Education level, age and gender may result in differentiation in individuals' emotional capability of maintaining self-confidence, and generating alternative solutions to obstacles and problems. For example, differences may occur in the aforesaid activities as the education level or age increases.

\section{Survey of San Diego City}

\subsection{Objective of the Survey}

The objective of the survey was to identify the relationship between the City of San Diego employees' learned helplessness level, seniority, position and demographic characteristics and their learned helplessness levels.

\subsection{Survey Method}

The survey was administered to the City of San Diego employees in the state of California, United States of America. The population consisted of approximately 10.000 employees. Participants to the survey were selected by random sampling method from among managers and staff of different units. 151 surveys were obtained from the population. A size of 151 samples appears to be sufficient for $a=0,05$, and $p=0,5 q=0,510 \%$ of sampling error.

This study is the first empirical research that investigates the impact of learned helplessness in the field of public administration. Being an exploratory research, a case study methodology was utilized that focused on the San Diego City administration. Based on the findings of this exploratory research, future studies that employ comparative methodology with a broader scope would be useful.

\subsection{Data Collection, Analysis of Data}

Although there are instruments to measure personal helplessness, no instrument is available for public employees. We therefore developed an original survey instrument to collect the data on public employees. The interview questions were provided on a 5 point likert scale (1: strongly agree, 2 agree, 3 . neutral 4 disagree, and 5 . strongly disgree). The survey instrument was composed of two sections. Section I contained 5 questions on position, seniority and demographic characteristics. Section II contained items that measure learned helplessness in the public sector. The two sections included a total of 24 questions. Data was collected by one of the investigators between August 2013 and April 2014. Data was then entered into and analyzed using SPSS (Statistical Package for Social Sciences) program.

\subsection{Survey Findings and Evaluation}

The Cronbach's Alpha is 0,880 . This indicates that reliability of the instrument is very high. Frequency distribution of the demographic characteristics of 151 participants is presented in Table 2. 
Table 2. Frequency Distribution

\begin{tabular}{ccc}
\hline Position & Frekans & $\%$ \\
\hline Management & 46 & 30,5 \\
Non-management & 102 & 67,5 \\
Missing & 3 & 2 \\
Total & 151 & 100 \\
Seniority & & \\
0-5 years & 24 & 15,9 \\
6-10 years & 34 & 22,5 \\
11-15 years & 36 & 23,8 \\
16-20 years & 15 & 9,9 \\
21 years and above & 42 & 27,8 \\
Total & 151 & 100,0 \\
Education & & \\
Primary & 4 & 2,6 \\
Secondary & 24 & 15,9 \\
College & 78 & 51,7 \\
Graduate & 43 & 28,5 \\
Missing & 2 & 1,3 \\
Total & 151 & 100 \\
Age & & \\
25 and & 11 & 7,3 \\
26-35 & 30 & 19,9 \\
36-45 & 39 & 25,8 \\
46-55 & 33 & 21,9 \\
56 and $>$ & 38 & 25,2 \\
Total & 151 & 100,0 \\
Gender & & 34,4 \\
Male & 52 & 2,6 \\
Female & 95 & 100 \\
Missing & & \\
Total & & \\
& & \\
\hline
\end{tabular}

In Table 2, demographic characteristics of respondents show that $30 \%$ were in the management positions and $67 \%$ were in non-management positions.

In evaluating their seniority as a public employee, $27.8 \%$ of the participants indicated having 21 years of seniority or more and only $15.9 \%$ had 5 years of seniority or less. In other words, a large portion of the participants (as many as $84 \%)$ had more than 5 years of seniority.

Table 3. Means of Responses to Items

\begin{tabular}{cccc}
\hline Items & $\mathrm{N}$ & Mean & Std. Deviation \\
\hline md6 & 151 & 2,4503 & 1,24198 \\
md7 & 148 & 2,9189 & 1,95359 \\
md8 & 147 & 2,8912 & 1,23382 \\
md9 & 148 & 3,5338 & 1,20326 \\
md10 & 150 & 2,9067 & 1,23889 \\
md11 & 149 & 2,7517 & 1,27823 \\
md12 & 149 & 2,7315 & 1,18339 \\
md13 & 149 & 3,1208 & 1,16197 \\
md14 & 151 & 3,0861 & 1,22714 \\
md15 & 150 & 3,0667 & 1,22976 \\
md16 & 149 & 2,9866 & 1,13296 \\
md17 & 151 & 3,0199 & 1,09830 \\
md18 & 148 & 3,2230 & 1,22236 \\
md19 & 150 & 3,3667 & 1,25006 \\
md20 & 150 & 3,4800 & 1,19124 \\
md21 & 151 & 3,2583 & 1,20810 \\
md22 & 151 & 3,6026 & 1,21699 \\
md23 & 151 & 3,6291 & 1,18668 \\
md24 & 151 & 3,8344 & 1,06727 \\
Valid N (listwise) & 129 & & \\
\hline
\end{tabular}


The way the questions and responses were framed in the survey, learned helplessness increased as the mean of response to each item approximated to 1, and learned helplessness decreased as the mean of response to each item approximated to 5. The overall mean of all items was 3.15. In view of this finding, City of San Diego employees do not present learned helplessness.

It appears to remain the same for the factors from the factor analyses. Factor mean "faith in being effective in the organization" was 3.52; "faith in making changes in the public administration system" was 2.90; and "desire to exert effort" was 3.07. According to these means, the highest divergence from learned helplessness was found in the item "faith in being effective in the organization" followed by "desire to exert effort" and lastly "faith in making changes to public administration system". In other words, employees self confidence or faith in being effective in the organization was higher than their self confidence or faith in making changes to public administration system among City of San Diego employees. According to attribution theory, this outcome indicates that employees did not attribute failure to themselves, thus they did not experience personal learned helplessness but they attributed failure to external factors, thus the level of organizational learned helplessness was slightly higher.

\subsubsection{Factor Analysis}

The factor analysis shows that KMO had a value as high as 0,913. Except for the item 7, diagonal values were very higher than 0.5 in Anti-Image Correlation matrix. In fact, most of the items had a value near 1, which indicates that factor analysis performed was very successful. To achieve a successful factor analysis, item 7 was excluded from the factor analysis because the diagonal value of this item was lower than 0.5 .

Table 4. Total Variance Explained

\begin{tabular}{|c|c|c|c|c|c|c|c|c|c|}
\hline \multirow[t]{2}{*}{ Component } & \multicolumn{3}{|c|}{ Initial Eigenvalues } & \multicolumn{3}{|c|}{$\begin{array}{l}\text { Extraction Sums of Squared } \\
\text { Loadings }\end{array}$} & \multicolumn{3}{|c|}{ Rotation Sums of Squared Loadings } \\
\hline & Total & $\begin{array}{c}\% \text { of } \\
\text { Variance }\end{array}$ & $\begin{array}{c}\text { Cumulative } \\
\%\end{array}$ & Total & $\begin{array}{c}\% \text { of } \\
\text { Variance }\end{array}$ & $\begin{array}{c}\text { Cumulative } \\
\%\end{array}$ & Total & $\begin{array}{c}\% \text { of } \\
\text { Variance }\end{array}$ & $\begin{array}{c}\text { Cumulative } \\
\%\end{array}$ \\
\hline 1 & 8,196 & 45,532 & 45,532 & 8,196 & 45,532 & 45,532 & 3,849 & 21,382 & 21,382 \\
\hline 2 & 1,819 & 10,104 & 55,636 & 1,819 & 10,104 & 55,636 & 3,798 & 21,099 & 42,481 \\
\hline 3 & 1,096 & 6,087 & 61,723 & 1,096 & 6,087 & 61,723 & 3,463 & 19,241 & 61,723 \\
\hline 4 & ,912 & 5,067 & 66,789 & & & & & & \\
\hline 5 &, 854 & 4,747 & 71,536 & & & & & & \\
\hline 6 & ,731 & 4,063 & 75,599 & & & & & & \\
\hline 7 &, 712 & 3,954 & 79,553 & & & & & & \\
\hline 8 &, 574 & 3,191 & 82,745 & & & & & & \\
\hline 9 &, 490 & 2,720 & 85,464 & & & & & & \\
\hline 10 & ,441 & 2,449 & 87,914 & & & & & & \\
\hline 11 & ,380 & 2,112 & 90,026 & & & & & & \\
\hline 12 & ,351 & 1,948 & 91,974 & & & & & & \\
\hline 13 & ,313 & 1,742 & 93,716 & & & & & & \\
\hline 14 &, 293 & 1,629 & 95,344 & & & & & & \\
\hline 15 & 262 & 1,456 & 96,800 & & & & & & \\
\hline 16 & ,233 & 1,292 & 98,092 & & & & & & \\
\hline 17 &, 210 & 1,164 & 99,257 & & & & & & \\
\hline 18 & 134 & ,743 & 100,000 & & & & & & \\
\hline
\end{tabular}

In Table 4, there are 3 factors with an eigenvalue of higher than 1 and these factors explain $61.723 \%$ of total variance. The explanation degree of each factor for total variance was $45,532 \%, 10,104 \%$, and $6,087 \%$ respectively. Varimax rotation was used to facilitate terming each factor. After rotating the factors, the factors loads were $21,382 \%, 21,099 \%$, and $19,241 \%$ respectively.

As a result of this rotation, the factors were termed as follows:

Factor 1: "faith in being effective in the organization",

Factor 2: "faith in making changes to public administration system".

Factor 3: "desire to exert effort".

The 3 factors resulted from the factor analysis are presented in Table 5 below. 
Table 5. Rotated Component Matrix

\begin{tabular}{cccc}
\hline & & Component & \\
\hline md23 & 1 & 2 & 3 \\
md22 &, 871 &, 187 &, 121 \\
md24 &, 851 &, 191 &, 247 \\
md20 &, 757 &, 176 &, 041 \\
md21 &, 697 &, 208 &, 424 \\
md19 &, 682 &, 176 &, 332 \\
md10 &, 548 &, 328 &, 538 \\
md8 &, 243 &, 800 &, 201 \\
md11 &, 223 &, 743 &, 102 \\
md12 &, 182 &, 725 &, 355 \\
md9 &, 035 &, 660 &, 444 \\
md6 &,- 128 &,- 623 &,- 116 \\
md13 &, 208 &, 592 &, 300 \\
md16 &,- 149 &,- 386 &, 344 \\
md17 &, 082 &, 218 &, 742 \\
md15 &, 237 &, 169 &, 730 \\
md18 &, 267 &, 301 &, 699 \\
md14 &, 303 &, 339 &, 459 \\
\hline
\end{tabular}

The factors consist of the following items in the survey (See Appendix A for a copy of the survey questionnaire)

Factor 1: items 19, 20, 21, 22, 23 and 24,

Factor 2: items 6, 8, 9, 10, 11, 12 and 13,

Factor 3: items 14, 15, 16, 17 and 18

5.4.2 Analysis of Differences in Factors for Seniority, Position and Demographic Characteristics

Using the 3 factors developed through the factor analysis described above, we developed the following hypotheses:

\subsection{Factor 1}

$\mathrm{H} 1=$ There is a significant difference in "faith in being effective in the organization" among public employees assigned to different positions.

$\mathrm{H} 2$ = There is a significant difference in "faith in being effective in the organization" among public employees with different seniority levels.

$\mathrm{H} 3=$ There is a significant difference in "faith in being effective in the organization" among public employees based on education levels.

$\mathrm{H} 4=$ There is a significant difference in "faith in being effective in the organization" among public employees based on age.

$\mathrm{H} 5=$ There is a significant difference in "faith in being effective in the organization" among public employees based on gender.

\subsubsection{Differences Observed in Factor 1 According to Position}

T test was performed to see whether a difference existed between manager positions and non-manager positions for Factor 1, "faith in being effective in the organization". The results of the T test analysis verified H1, which suggested that there is a significant difference in "faith in being effective in the organization" among employees assigned to different positions in public organizations. A significant difference was present in the groups according to the results of Leven test (Sig. 0,958; Sig.2- tailed 0,000).

As shown in Table 6, mean of Factor 1 for managers is higher than that of non-managers. That is, managers had higher faith in being effective in the organization than non-managers because they had less power in the public administration system; and non-managers experienced more learned helplessness as they were less powerful to control or change situations. 
Table 6. Differences Observed in Factor 1 According to Position

\begin{tabular}{cccccc}
\hline & Position & N & Mean & Std. Deviation & Std. Error Mean \\
\hline \multirow{2}{*}{ SMEAN(fak1) } & Management & 46 & 3,9638 &, 96155 &, 14177 \\
& Non-management & 102 & 3,3340 &, 92319 &, 09141 \\
\hline
\end{tabular}

\subsubsection{Differences Observed in Factor 1 According to the Seniority}

One-way ANOVA test was performed to see whether a difference existed in Factor 1, "faith in being effective in the organization", between the different groups of seniority. According to the results of the analysis, hypothesis $\mathrm{H} 2 \mathrm{has}$ been verified, meaning there is a significant difference between public employees' faith in being effective in the organization based on their seniority in the public sector(F=4,369; Sig. 0,002). Test results are presented in Table 7.

Table 7. Differences in Factor 1 According to Seniority

\begin{tabular}{lccccc}
\hline \multirow{2}{*}{ (I) Seniority (J) Seniorit } & \multirow{2}{*}{ Mean Difference (I-J) } & \multirow{2}{*}{ Std. Error } & \multirow{2}{*}{ Sig. } & \multicolumn{2}{c}{$95 \%$ Confidence Interval } \\
\cline { 4 - 6 } & & & & Lower Bound & Upper Bound \\
\hline 0-5 years 6-10 years &, $81454^{*}$ &, 24781 &, 033 &, 0414 & 1,5877 \\
\hline *The mean difference is significant at the 0.05 level.
\end{tabular}

In this table, a significant difference existed between the seniority group of $0-5$ years and the seniority group of $6-10$ years for "faith in being effective in the organization". Those with a seniority of 0-5 years had a higher score than those with a seniority of 6-10 years. In other words, those with a seniority of 6-10 years had less faith in being effective in the organization and exhibited more tendency to learned helplessness than those with a seniority of 0-5 years. There were no significant differences between the other groups of seniority and the faith in being effective in the organization. In a sense, this suggests that those with a seniority of 0-5 years had a lower tendency to learned helplessness than that of those with a seniority of 6-10 years because they were newly assigned to the public sector; tendency to helplessness increased in the second group of seniority after 5-10 years; and tendency to helplessness did not continue increasing as the employee was promoted during subsequent years. In some respect, difference in helplessness after 5 years of business experience appears to come out during the seniority of 6-10 years.

\subsubsection{Differences Observed in Factor 1 According to the Education}

One-way ANOVA test was performed to see whether a difference existed between education levels for Factor 1, "faith in being effective in the organization". According to the results of analysis, the hypothesis H3 has been verified, which suggested that there is a significant difference in faith in being effective in the organization among public employees based on education level ( $F=9,568$; Sig. 0,000). Test results are presented in Table 8.

Table 8. Differences in Factor 1 According to Education

\begin{tabular}{ccccccc}
\hline \multirow{2}{*}{$(\mathrm{I})$ Education (J) Education } & \multirow{2}{*}{ Mean Difference (I-J) } & \multirow{2}{*}{ Std. Error } & \multirow{2}{*}{ Sig. } & \multicolumn{2}{c}{ 95\% Confidence Interval } \\
\cline { 5 - 7 } & & & & & Lower Bound & Upper Bound \\
\hline \multirow{2}{*}{ University } & Highschool &, $64468^{*}$ &, 20948 &, 027 &, 0521 & 1,2372 \\
Post-graduate & Highschool & $1,20849^{*}$ &, 22866 &, 000 &, 5617 & 1,8553 \\
& University &, $56382^{*}$ &, 17045 &, 014 &, 0817 & 1,0460 \\
\hline
\end{tabular}

*The mean difference is significant at the 0.05 level.

A significant difference in "faith in being effective in the organization" was observed between university graduates and high-school graduates; between employees with postgraduate degrees and high-school graduates; and between employees with postgraduate degrees and university graduates. University graduates had a higher score than the highschool graduates; employees with postgraduate degrees had a higher score than high-school graduates; and those with postgraduate degrees had a higher score than those with university degree. This shows that high-school graduates have less faith in being effective in the organization and exhibited more tendency for learned helplessness compared to the university graduates or postgraduates. Similarly, university graduates showed less faith in being effective in the organization than those with postgraduate degrees. No significant differences were present between the other groups of 
education level for Factor 1. This result indicates that there is a relationship between education level and learned helplessness in certain groups of education, and learned helplessness decreases as the education level increases. This might be due to the fact that as the education level of an employee increases so does his/her power in the organization, which leads to higher faith in being effective in the organization.

\subsubsection{Differences Observed in Factor 1 Based on Age}

One-way ANOVA test was performed to see whether a difference existed between the age groups for Factor 1, "faith in being effective in the organization". According to the results of analysis, hypothesis $\mathrm{H} 4 \mathrm{has}$ been verified, which suggested that there is a significant difference in faith in being effective in the organization among employees in different age groups in public organizations ( $F=5,482$; Sig. 0,000). Test results are presented in Table 9.

Table 9. Differences Observed in Factor 1 Based on Age

\begin{tabular}{ccccccc}
\hline \multicolumn{2}{c}{ (I) Age J } & \multirow{2}{*}{ Mean Difference (I-J) } & \multirow{2}{*}{ Std. Error } & \multirow{2}{*}{ Sig. } & \multicolumn{2}{c}{$95 \%$ Confidence Interval } \\
\cline { 5 - 7 } & & & & & Lower Bound & Upper Bound \\
\hline \multirow{2}{*}{56 and > $>$} & $26-35$ &, $76316^{*}$ &, 22398 &, 024 &, 0643 & 1,4620 \\
& $36-45$ &, $83617^{*}$ &, 20904 &, 004 &, 1839 & 1,4884 \\
\hline
\end{tabular}

*The mean difference is significant at the 0.05 level.

Significant differences between the age group 56 and above and the age group 26-35 years; and the age group 56 and above and the age group 36-45 were observed in "faith in being effective in the organization". The age group of 56 and > had a higher score of 0,76316 compared to the age group of 26-35, and of 0,83617 compared to the age group of 36-45. In other words, the age groups of 26-35 years and 36-45 years had less faith in being effective in the organization and displayed more tendency to learned helplessness compared to the age group of 56 and above. No significant differences were observed between the other age groups. This result indicates that with age faith in being effective in the organization increases and tendency for learned helplessness decreases. This may be due to the fact that employees learn to cope with learned helplessness as they mature.

\subsubsection{Differences Observed in Factor 1 According to Gender}

T test was performed to see whether a difference existed between female and male employees for Factor 1, "faith in being effective in the organization". According to the results of analysis, the hypothesis $\mathrm{H} 5$ has not been verified, which suggested that there is not a significant difference in faith in being effective in the organization between male and female employees in public organizations. According to the results of Leven test (Sig. 0,144; Sig.2- tailed 0,805), no significant differences were present between the groups. According to this result, gender does not appear to be a determinant for faith in being effective in the organization and thus for learned helplessness.

\subsection{Factor 2}

Factor 2 is the "faith in making changes to public administration system". The hypotheses determined for Factor 2 are provided below:

$\mathrm{H} 1=$ There is a significant difference among public employees' "faith in making changes to public administration system" based on their position in the workplace.

$\mathrm{H} 2$ = There is a significant difference among public employees' "faith in making changes to public administration system" based on their seniority level in the workplace.

H3 = There is a significant difference among public employees' "faith in making changes to public administration system" based on their education level.

$\mathrm{H} 4=$ There is a significant difference among public employees' "faith in making changes to public administration system" based on age.

$\mathrm{H} 5=$ There is a significant difference among public employees' "faith in making changes to public administration system" based on gender. 


\subsubsection{Differences Observed in Factor 2 According to the Position}

T test was performed to see whether a difference existed between the directors and the non-directors for Factor 2, i.e. "faith in making changes to public administration system". According to the results of analysis, hypothesis $\mathrm{H} 1 \mathrm{has}$ been verified, which suggested that there is a significant difference among employees working at different positions in public organizations with regard to how much faith they have in making changes to public administration system. There were significant differences between the groups according to the results of Leven test (Sig. 0,099; Sig.2- tailed 0,000).

Table 10. Differences Observed in Factor 2 According to the Position

\begin{tabular}{cccccc}
\hline \multicolumn{2}{c}{ Position } & $\mathrm{N}$ & Mean & Std. Deviation & Std. Error Mean \\
\hline \multirow{2}{*}{ SMEAN(fak2) } & Management & 46 & 3,1768 &, 59327 &, 08747 \\
& Non-mgt. & 102 & 2,8083 &, 52891 &, 05237 \\
\hline
\end{tabular}

Table 10 presents the means of Factor 2 for managers and non managers. The mean for Factor 2 is higher for public employees with management positions than that of those with non-management positions. That is, managers show a higher faith in making changes to public administration system than those with non-management positions. This may be due to the fact that public employees with non-management positions have less decision making power in the overall public administration system and this sense of powerlessness leads to increased learned helplessness.

\subsubsection{Differences Observed in Factor 2 According to the Seniority}

One-way ANOVA test was performed to see whether a difference existed between the groups of different seniority levels for Factor 2, "faith in making changes to public administration system". According to the results of analysis, hypothesis $\mathrm{H} 2$ has been verified, which suggested that there is a significant difference among public employees with different seniority levels $(F=2,502$; Sig. 0,045). In other words, a relationship was identified between the "faith in making changes to public administration system" and the seniority and thus the helplessness.

\subsubsection{Differences Observed in Factor 2 According to the Education}

One-way ANOVA test was performed to see whether a difference existed between employees wit different education levels for Factor 2, "faith in making changes to public administration system". According to the results of analysis, hypothesis H3 has not been verified ( $F=1,096$; Sig. 0,353). In other words, no significant differences were found between the education levels of public employees and their faith in making changes to public administration system. This is a non finding that requires more future research.

\subsubsection{Differences Observed in Factor 2 According to the Age}

One-way ANOVA test was performed to see whether a difference existed in different age groups for Factor 2, "faith in making changes to public administration system". According to the results of analysis, hypothesis $\mathrm{H} 4$ has not been verified ( $F=2,228$; Sig. 0,69). As such, age level appears to be insignificant for public employees' faith in making changes to public administration system.

\subsubsection{Differences Observed in Factor 2 According to the Gender}

T test was performed to see whether a difference existed between male and female employees for Factor 2, "faith in making changes to public administration system". According to the results of analysis, hypothesis H5 has not been verified, which suggested that there is a significant difference between the female and the male employees in public organizations for "faith in making changes to public administration system". No significant differences were present between the groups in the results of Leven test (Sig. 0,264; Sig.2- tailed 0,947). In light of this result, gender does not appear to be a determinant for "faith in making changes to public administration system" and thus learned helplessness. 


\subsection{Factor 3}

The following hypotheses were developed for Factor 3, "desire to exert effort":

$\mathrm{H} 1=$ There is a significant difference among the employees working at different positions in public organizations for "desire to exert effort".

$\mathrm{H} 2$ = There is a significant difference among the employees with different seniority levels in public organizations for "desire to exert effort".

$\mathrm{H} 3=$ There is a significant difference among the employees with different education levels in public organizations for "desire to exert effort".

$\mathrm{H} 4=$ There is a significant difference among the employees in different age groups for "desire to exert effort".

$\mathrm{H} 5=$ There is a significant difference between the female and the male employees in public organizations for "desire to exert effort".

\subsubsection{Differences Observed in Factor 3 According to the Position}

T test was performed to see whether a difference existed between the managers and the non-managers for Factor 3 , "desire to exert effort". According to the results of this analysis, hypothesis $\mathrm{H} 1$ has been verified, which suggested that there is a significant difference among the employees working at different positions in public organizations for "desire to exert effort". Significant differences were observed between the two groups in the Leven test (Sig. 0,741; Sig.2- tailed $0,000)$.

Table 11. Differences Observed in Factor 3 According to the Position

\begin{tabular}{cccccc}
\hline & Position & N & Mean & Std. Deviation & Std. Error Mean \\
\hline \multirow{2}{*}{ SMEAN(fak3) } & Management & 46 & 3,5609 &, 83439 &, 12302 \\
& Non-management & 102 & 2,8576 &, 87207 &, 08635 \\
\hline
\end{tabular}

Table 11 presents the means of Factor 3. The mean for managers for Factor 3 is higher than that of non-managers. That means, managers have a higher "desire to exert effort" than those with non-manager position. This indicates those with non-manager position have a lower desire to exert effort and thus have increased tendency towards learned helplessness. This further supports the fact that public employees with less power and authority experience more learned helplessness.

\subsubsection{Differences Observed in Factor 3 According to the Seniority}

One-way ANOVA test was performed to see whether a difference existed between the groups of seniority for Factor 3 , i.e. "desire to exert effort". According to the results of analysis, the hypothesis $\mathrm{H} 2$ has been verified, which suggested that there is a significant difference among the employees with different seniorities in public organizations for "desire to exert effort ( $F=3,324$; Sig. 0,012).

Table 12. Differences Observed in Factor 3 According to the Seniority

\begin{tabular}{|c|c|c|c|c|c|c|}
\hline \multirow{2}{*}{\multicolumn{2}{|c|}{ (I) Seniority (J) Seniority }} & \multirow{2}{*}{ Mean Difference (I-J) } & \multirow{2}{*}{ Std. Error } & \multirow{2}{*}{ Sig. } & \multicolumn{2}{|c|}{ 95\% Confidence Interval } \\
\hline & & & & & Lower Bound & Upper Bound \\
\hline $0-5$ years & $11-15$ years & ,65222* & ,23276 & 045 & ,0093 & 1,2951 \\
\hline
\end{tabular}

${ }^{*}$ The mean difference is significant at the 0.05 level.

Those with a seniority of 6-10 years at the job had a higher score of 0,65222 than those with a seniority of 11-5 years for "desire to exert effort". In other words, those with a seniority of 11-15 years had lower desire to exert effort and thus illustrated higher learned helplessness than those with a seniority of 0-5 years. This result may indicate that learned helplessness increases as the employee's tenure increases. 


\subsubsection{Differences Observed in Factor 3 According to the Education}

One-way ANOVA test was performed to see whether a difference existed between public employees' desire to exert effort based on differences in educational level. According to the results of analysis, hypothesis H3 has been verified, which suggested that there is a significant difference among the employees with different education levels in public organizations for "desire to exert effort" ( $F=2,887$; Sig. 0,038). Test results are presented in Table 13.

Table 13. Differences Observed in Factor 3 According to the Education

\begin{tabular}{lcccccc}
\hline \multirow{2}{*}{$(\mathrm{I})$ Education (J) Education } & \multirow{2}{*}{ Mean Difference (I-J) } & \multirow{2}{*}{ Std. Error } & \multirow{2}{*}{ Sig. } & \multicolumn{2}{c}{$95 \%$ Confidence Interval } \\
\cline { 5 - 7 } & & & & Lower Bound & Upper Bound \\
\hline Postgraduate & Highsch. &, $65709^{*}$ &, 22750 &, 043 &, 0136 & 1,3006 \\
\hline
\end{tabular}

* The mean difference is significant at the 0.05 level.

We have identified a significant difference between those with a post-graduate degree and those with high-school degree with respect to "desire to exert effort". Those with a postgraduate degree had a higher score of 0,65709 than high-school graduates. In other words, high-school graduates lost their desire to exert effort and displayed tendency to learned helplessness more than those with postgraduate degrees did. No significant differences were found between other education groups for desire to exert effort. This result may indicate that there was a relationship between the education level and the learned helplessness for certain education groups; helplessness decreased as the education level increased and the potential to remain strong in the public administration system increased.

\subsubsection{Differences Observed in Factor 3 According to the Age}

One-way ANOVA test was performed to see whether a difference existed in Factor 3, "desire to exert effort" based on age. According to the results of analysis, hypothesis $\mathrm{H} 4$ has been verified, which suggested there is a significant difference among the employees in different age groups for "desire to exert effort" ( $F=3,003$; Sig. 0,020).

Table 14. Differences Observed in Factor 3 According to the Age

\begin{tabular}{|c|c|c|c|c|c|c|}
\hline \multirow{2}{*}{\multicolumn{2}{|c|}{ (I) Age (J) Age }} & \multirow{2}{*}{ Mean Difference (I-J) } & \multirow{2}{*}{ Std. Error } & \multirow{2}{*}{ Sig. } & \multicolumn{2}{|c|}{ 95\% Confidence Interval } \\
\hline & & & & & Lower Bound & Upper Bound \\
\hline 56 and $>$ & $36-45$ &, $57379^{*}$ & ,20215 & ,041 & ,0154 & 1,1322 \\
\hline
\end{tabular}

* The mean difference is significant at the 0.05 level.

The age group of 56 and above had a higher score of 0,57379 than the age group 36-45. In other words, the age group 36-45 had less desire to exert effort and thus illustrated higher learned helplessness than those in the age group of 56 and above. No significant differences were identified between the other age groups. This result indicates that public employees aged 56 and above had increased desire to exert effort and decreased learned helplessness. Since this result contradicts our finding on seniority, more research has to be done to flesh out the impact of seniority and age on desire to exert effort in an organization.

\subsubsection{Differences Observed in Factor 3 According to the Gender}

T test was performed to see whether a difference existed between male and female employees for Factor 3 , "desire to make effort". According to the results of analysis, hypothesis H5 has not been verified, which suggested that there is a significant difference between the female and the male employees in public organizations for "desire to exert effort". In the results of Leven test (Sig. 0,953; Sig.2- tailed 0,627), no significant differences were found between the groups. This result suggests that gender is not a determinant for "desire to exert effort" and thus does not have a direct effect on learned helplessness.

\section{Conclusions}

This research examined the learned helplessness levels of City of San Diego employees and its relationship with 
seniority, position and demographic factors. Overall, no significant tendency towards learned helplessness was identified in City of San Diego employees. Furthermore, our findings suggest that a positive or negative relationship exist between position, seniority, education and age, and learned helplessness in public organizations, while no significant relationship was found between gender and learned helplessness.

According to factor analysis, the highest divergence from learned helplessness was found in "faith in being effective in the organization" followed by "desire to exert effort" and lastly "faith in making changes to public administration system". This suggests that City of San Diego employees display highest level of faith in being effective in the organization, and least level of faith in making changes in the public administration system. This outcome indicates that public employees maintain more confidence and faith in personal effort and control in their specific organization or unit, than the faith control over the overall system. According to attribution theory, this outcome may indicate that these employees do not attribute failure to themselves (personal causes), thus they did not experience personal helplessness. Instead they attributed the state of failure to external factors, thus the level of organizational helplessness was slightly higher.

The study found that significant differences existed in position, seniority, education, and age for the three factors developed from the factor analyses:

A significant difference was identified between the position and three factors, "faith in being effective in the organization", "faith in making changes to the public administration system", and "desire to exert effort". Thus, whether a person had a management position or not appeared to have an influence on learned helplessness.

A significant difference was identified between the seniority and three factors, "faith in being effective in the organization", "faith in making changes to the public administration system", and "desire to exert effort". Thus seniority appeared to have an influence on learned helplessness.

A significant difference was identified between education and two factors, i.e. "faith in being effective in the organization", and "desire to exert effort". Thus, education appeared to have an influence on learned helplessness.

A significant difference was identified between age and two factors, i.e. "faith in being effective in the organization", and "desire to exert effort". Thus, age appeared to have an influence on learned helplessness.

No significant difference was identified between gender and the three factors, "faith in being effective in the organization", "faith in making changes to the public administration system", and "desire to exert effort". Thus, gender appeared to have no influence on learned helplessness.

This research topic was the first applied study to examine factors that affect learned helplessness in the public sector. Further comprehensive studies on public administration system of different countries would help shed more light on these determinants and how they work in different socio-political contexts.

\section{References}

Abramson LY, Seligman ME (1978), Learned Helplessness in Humans: Critique and Reformulation. J. Abnormal Psychol., 87(1): 49-74 David G (1993), Building A Learning Organization. Harv. Bus. Rev., 7/8:78-91, Espejo R-S, Werner S, Markus-Bilello U (1994). Organizational Transformation and Learning. Willey and Sons. England.

Günay KB, Oral N (2006), A Revision of The Learned Helplessness For Children. J. Mental Health Children Youngsters, 13(2).

Hiroto DS (1974), Locus of Control and Learned Helplessness. J. Exp. Psychol., 102(2): 187-193.

Hiroto DS, Seligman MEP (1975), Generality of Learned Helplessness in Men. J. Pers. Soc. Psychol., 31: 311-327.

Hunziker MHL, Santos CVD (2007), Learned Helplessness:Effects of Response Requirement and Interval Between Treatment and Testing. Behav. Proc., 76: 183-191.

Kümbül GB (2006). Learned Helplessness in Business Life. Liberte Publications. Ankara

Maier SF, Seligman MEP (1976), Learned Helplessness:Theory and Evidence. J. Exp. Psychol., 105(1): 3-46.

Overmier JB (2002), On Learned Helplessness. Integ. Physiol. Behav.Sci., 37(1): 4-8.

Seligman MEP, Maier SF (1967), Failure to Escape Traumatic Shock. J. Exp. Psychol., 74(1): 1-9.

Young LD, Allin JM (1992), Repression-Sensitization Differences in Recovery From Learned Helplessness. J. Gen. Psychol.,119(2): 135-139.

Yüksel F., Özkiraz A.(2012), "The main problem of Turkish public administration: Learned helplessness", African Journal of Business Management Vol. 6(4), pp. 1214-1221.

\section{Appendix A}

This survey, conducted is a scientific study on helplessness felt by individuals working in the field of public administration. The findings will be used entirely for scientific purposes. The names and institutions have no importance. Please answer the questions sincerely, for it will provide a major contribution to important scientific work. The survey will take about 10-15 minutes. Thank you in advance for your 
time and support.

\section{Your position in the organization}
( ) Manager/Director
( ) Not a manager

2. For how many years have you worked for the public administration
( ) $0-5$
( ) 6-10
( ) $11-15$
( ) $16-20$
( ) 21 and over

3. Education level

( ) Elementery ( ) High School

( ) College/University

( ) Graduate/Doctorate

4. Age
() 25 and under
( ) 26-35
( ) $36-45$
( ) 46-55
( ) 56 and over

5. Gender

( ) Female () Male

Check the response that best reflects your opinion to the following statements

\begin{tabular}{|c|c|c|c|c|c|}
\hline & 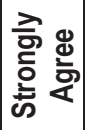 & 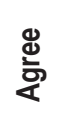 & 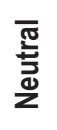 & 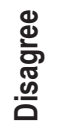 & 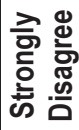 \\
\hline \multicolumn{6}{|l|}{ 6. It is hard to create change in the public institutions } \\
\hline \multicolumn{6}{|l|}{ 7. The existing structure of the public administration is prone to failure } \\
\hline \multicolumn{6}{|l|}{$\begin{array}{l}\text { 8. It is best not to try to change the existing structure of the public administration and do } \\
\text { your best within the system }\end{array}$} \\
\hline \multicolumn{6}{|l|}{ 9. Change is possible in the public institutions if employees are motivated } \\
\hline \multicolumn{6}{|l|}{$\begin{array}{l}\text { 10. In the public institutions the tasks are ostensive and ceremonial because of a lack of } \\
\text { belief that change is not going to be created. }\end{array}$} \\
\hline \multicolumn{6}{|l|}{$\begin{array}{l}\text { 11. In the public institutions decisions are made by top administrators. Public empolyees do } \\
\text { not have opportunties to participate in the decision making process or express their views. }\end{array}$} \\
\hline \multicolumn{6}{|l|}{ 12. The rules and norms in the public institutions push employees to be subservient } \\
\hline \multicolumn{6}{|l|}{ 13. It is easy to implement regulations in the public administration } \\
\hline \multicolumn{6}{|l|}{$\begin{array}{l}\text { 14. Employees in the public institutions do not utilize their talent and knowledge to the } \\
\text { fullest because they do not believe it will make a difference. }\end{array}$} \\
\hline \multicolumn{6}{|l|}{$\begin{array}{l}\text { 15. In the public institutions employees are rewarded if they do not complain about } \\
\text { problems }\end{array}$} \\
\hline \multicolumn{6}{|l|}{ 16. Public employees are in a psychological state of exhaustion } \\
\hline \multicolumn{6}{|l|}{$\begin{array}{l}\text { 17. Public employees receive negative reactions from peers and superiors if they do not } \\
\text { folllow the routines. }\end{array}$} \\
\hline \multicolumn{6}{|l|}{ 18. Since being hired I have lost my spirit of creating change } \\
\hline \multicolumn{6}{|l|}{ 19. No matter how much energy I put into a task, I feel I have no control over the outcome. } \\
\hline \multicolumn{6}{|l|}{ 20. I cannot find solutions to difficult problems related to my work. } \\
\hline \multicolumn{6}{|l|}{ 21. I don't place myself in situations in which I cannot succeed } \\
\hline \multicolumn{6}{|l|}{ 22. If I complete a task successfully, it is probably because I was lucky. } \\
\hline \multicolumn{6}{|l|}{$\begin{array}{l}\text { 23. When I do not succeed at a task I do not attempt any similar tasks because I feel that I } \\
\text { will fail them also }\end{array}$} \\
\hline 24. Despite my efforts at work I am unsuccessful at most tasks I try. & & & & & \\
\hline
\end{tabular}

